\title{
Influence of Molecular Sieves Is Added in the Thermal Decomposition of Rice Husk
}

\author{
N. Morita, M. Nakayasu, Y. Kawabata, and H. Nakagome
}

\begin{abstract}
This research reports the energy release of rice chaff by pyrolysis. In Southeast Asia, rice is a staple food, and an abundance of chaff remains after rice cleaning the rice. Most chaff is spread on farmland or used as livestock feed. However, there is still a large amount of discarded chaff. In this study, This research was gasified chaff to evaluate its energy conversion using pyrolysis. This research investigated the effect of molecular sieves, which are a column filler, as an additive. The pyrolysis was performed under highly efficient conditions to measure any catalytic effects. Methane gas is a decomposition product and its release was the focus of this work as well as analyzing the amount of emitted carbon dioxide Adding molecular sieves $3 \mathrm{~A}$ increases methane gas release and decreases carbon dioxide.
\end{abstract}

Index Terms-Molecular sieve, pyrolysis, rice husk.

\section{INTRODUCTION}

Interest is increasing for the utilization of biomass resources because fossil fuels are drying up and environmental protection is becoming more important worldwide [1].

Not only for the utilization of biomass resources, pyrolysis is important for effective chemical conversion in other fields such as recycling. There are abundant studies investigating pyrolysis and chemical recycling [2]-[13], but pyrolysis is a complicated process influenced by many factors [14]-[17]. The main component of lignocellulosic biomass is hemicellulose, cellulose, and lignin at contents around $20-40 \%, 40-60 \%$, and $10-25 \%$, respectively [18].

Lignin is gradually broken down in a wide temperature range of $280-600{ }^{\circ} \mathrm{C}$, and hemicellulose and cellulose can decompose quickly at low temperatures around $200-350{ }^{\circ} \mathrm{C}$ [19].

The char and liquid compound yield decrease when pyrolysis of biomass is performed at a high temperature, and the quantity of emitted gases increases, but the yield of the gas decreases at low pyrolysis temperatures. The cracking of liquid hydrocarbons promotes the formation of gases, and the cracking of a gaseous hydrocarbon promotes the formation of $\mathrm{H}_{2}$ [20]-[26]. Plants containing mainly wood, wood processing waste, energy crops, and farm products, as well as parts of organic waste, city garbage, and sewage grime can be

Manuscript received October 25, 2016; revised December 25, 2016.

N. Morita, M. Nakayasu, and Y. Kawabata are with the Department of Urban Environment Systems, Graduate School of Engineering, Chiba University, Japan (e-mail: Naoyuki_Morita@chiba-u.ne.jp, Masami_1_Nakayasu@education.metro.tokyo.jp,

tanoshimokita@gmail.com).

H. Nakagome is with Chiba University, Japan (e-mail: nakagome@tu.chiba-u.ne.jp). used for biomass in energy conversion [27], [28].

The biomass is available widely and carbon neutral, creating a fuel source with a lower carbon footprint than fossil fuels as an energy supply [29], [30].

The zeolite catalyst, molecular sieves, used under atmospheric pressure in dehydration has been reported as eco-friendly [31]. In addition, the zeolite catalyst has shown high performance in biomass pyrolysis, lowering the expense compared with alternatives such as high-pressure hydrogenation [32]. We have reported the increase of product oil by pyrolysis of plastics by adding molecular sieves [33]-[36].

In this study, aimed to analyze the change in the product gas quantities during pyrolysis at $700{ }^{\circ} \mathrm{C}$ when using molecular sieves as an additive and the change in the combustible gas amounts.

\section{EXPERIMENTAL}

\section{A. Materials}

The biomass sample was Japanese rice chaff Koshihikari from Yamanashi Prefecture, Japan. Molecular sieves 3A, 4A, $5 \mathrm{~A}$, and $13 \mathrm{X}$ as rods $1 / 16$ inch in length were purchased from Wako Pure Chemical Industries Co., Ltd, Osaka, Japan.

Sea sand (methanol washing product, $425-850 \mu \mathrm{m}$, Wako Pure Chemical Industries Co., Ltd.) was used as a control additive. The experiment conditions are shown in Table I.

TABLE I: EXPERIMENT CONDITIONS OF RICE HUSK (RH) PYROLYSIS

\begin{tabular}{cc} 
& \multicolumn{2}{c}{ Experiment Condition } \\
\hline I & Rice Husks \\
II & RH + Molecular Sieves 3A (1:1) \\
III & RH + Molecular Sieves 5A (1:1) \\
IV & RH + Molecular Sieves 13X (1:1) \\
V & RH + Molecular Sieves 3A Powder (1:1) \\
VI & $\mathrm{RH}+$ Molecular Sieves 5A Powder (1:1) \\
VII & $\mathrm{RH}+$ Molecular Sieves 13X Powder (1:1) \\
VIII & RH + Sea Sand (1:1) \\
\hline \hline
\end{tabular}

\section{B. Pyrolysis}

The experimental device is shown in Fig. 1. Twenty grams of chaff and any additive ( $20 \mathrm{~g}$ ) were placed inside the glass reactor and flushed with nitrogen gas for 60 minutes at 50 $\mathrm{mL} / \mathrm{min}$ to remove oxygen.

The flow of nitrogen gas was stopped for the pyrolysis tests. The sample part of the glass reactor was heated and monitored using a thermocouple from room temperature to $700{ }^{\circ} \mathrm{C}$ at 


\section{$10{ }^{\circ} \mathrm{C} / \mathrm{min}$.}

The gas generated during pyrolysis passed into a condenser and was collected in a container as pyrolysis acid. The non-condensable gas was collected using a gas pack by bubbling through an aqueous alkaline solution.

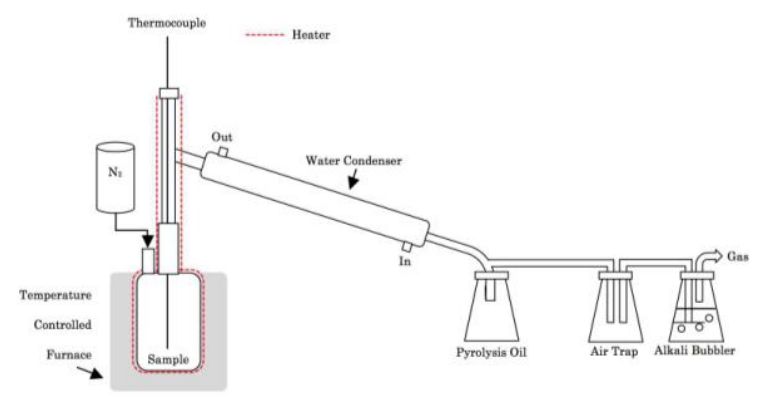

Fig. 1. Experimental apparatus.

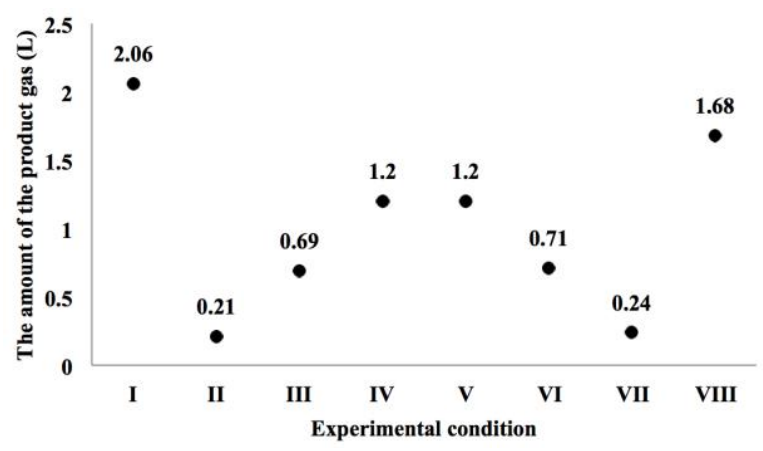

Fig. 2. Product gas release.

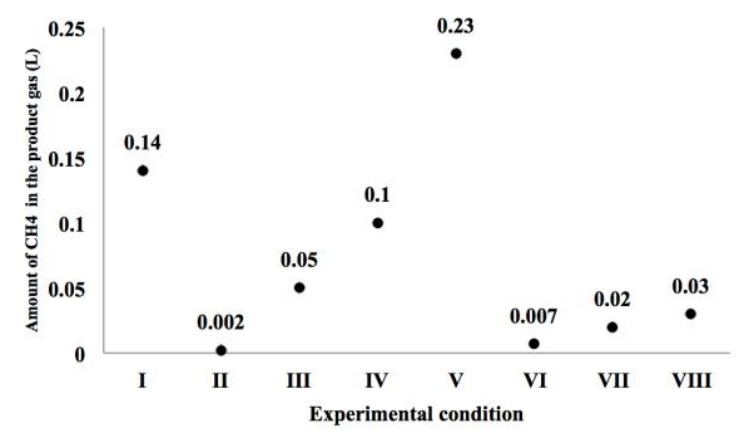

Fig. 3. Methane release.

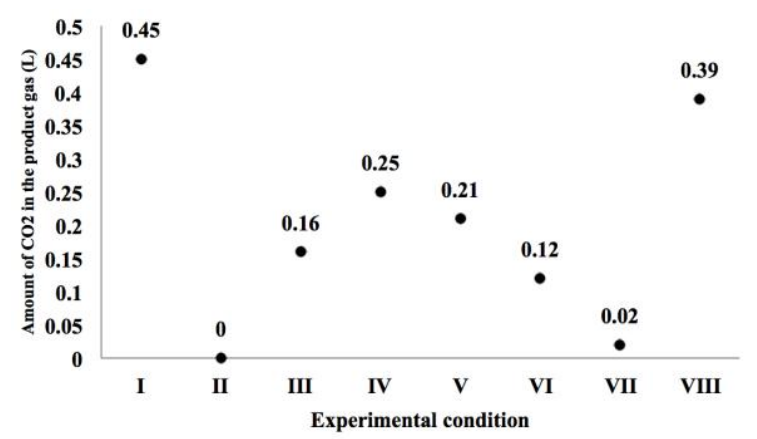

Fig. 4. Carbon dioxide release.

\section{Analysis}

Qualitative and quantitative analyses were performed using gas chromatography on a Shimadzu GC2014 (Kyoto, Japan) equipped with a flame ionization detector.

The residual substance was analyzed with a Hitachi TM3030 scanning electron microscope coupled with energy dispersion spectroscopy (EDS; Bruker QUANTAX, Billerica, MA, USA).
The surface of each sample was element distribution mapped using EDS to measure residual carbon.

\section{RESULTS AND DISCUSSION}

\section{A. Decomposition Gas}

Fig. 2 shows the product gas amounts from the different pyrolysis conditions. In addition, methane quantities are shown in Fig. 3, and carbon dioxide in Fig. 4.

As shown in Fig. 2, condition I, which was a condition without additive, generated the highest amount of product gas. Condition V, with powder-form molecular sieves $3 \mathrm{~A}$ at $1: 1$ ratio with rice husk showed the highest methane production, nearly double that of condition I (Fig. 3) and decreased carbon dioxide release to half that of condition 1 (Fig. 4).

\section{B. Residue Analysis}

In this study, EDS was used to observe residues on the sample surface and element distribution mapping to measure residual carbon was performed (Fig. 5). Residual carbon and residual oxygen in all conditions are shown in Fig. 6. Condition VI requires verification again, but since the remaining value shows a generally constant value, it can be said that it was properly pyrolysis under all conditions. The surface carbon content of rice hulls before thermal decomposition was $24.17 \%$. The amount of surface carbon from state I without additives after pyrolysis decreased to $17.09 \%$.

This decrease was due to the surface carbon becoming gas. Condition $\mathrm{V}$ using powdered molecular sieve $3 \mathrm{~A}$ as an additive showed that methane gas production efficiency was high because residual carbon decreased to $18.11 \%$ and methane release was higher than condition I.
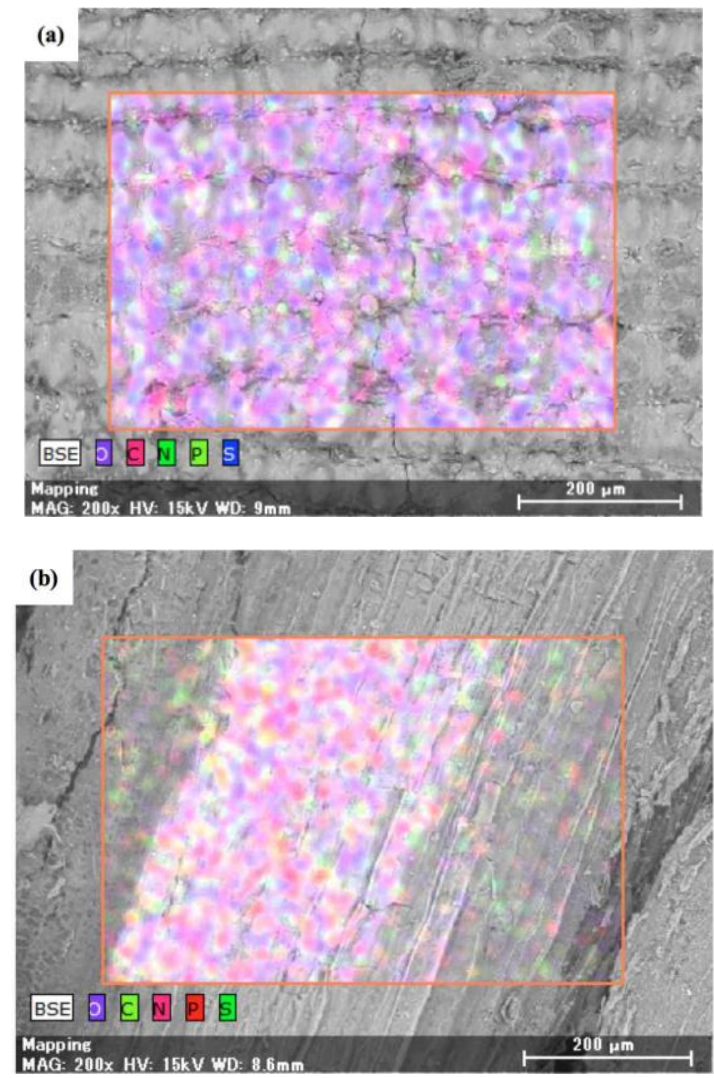


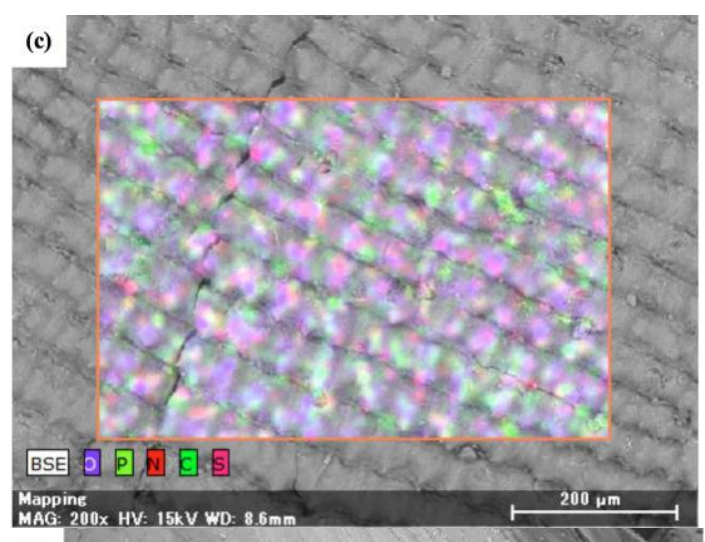

(d)
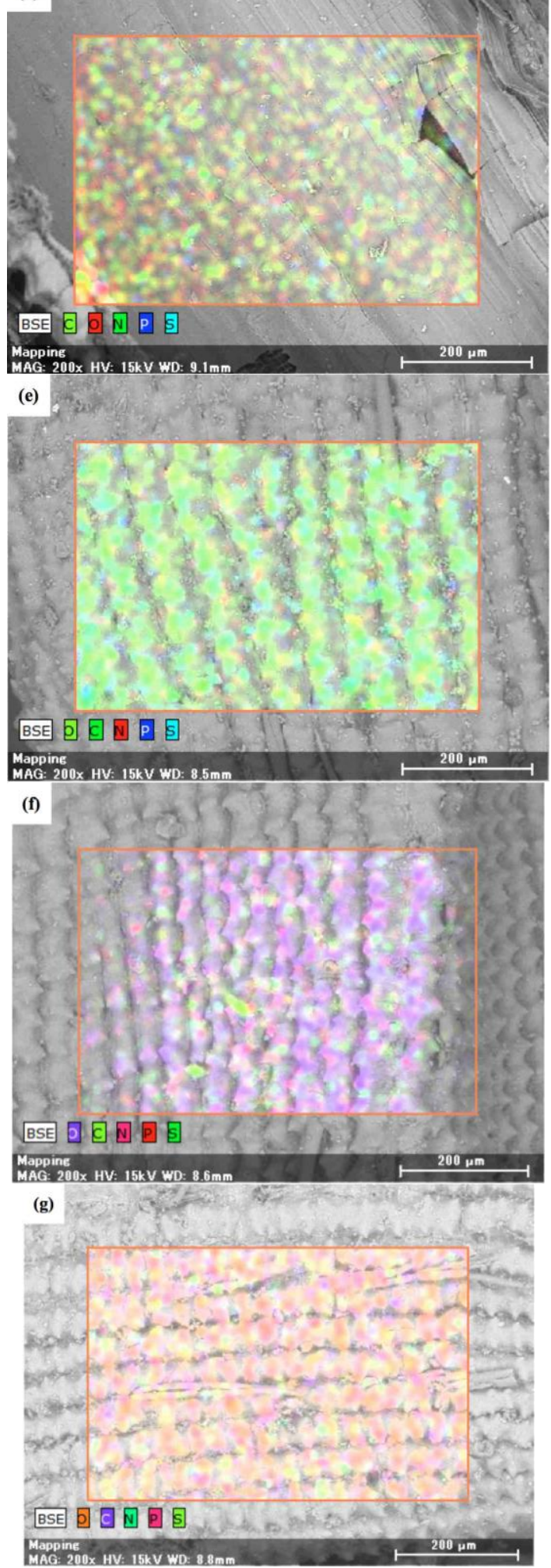

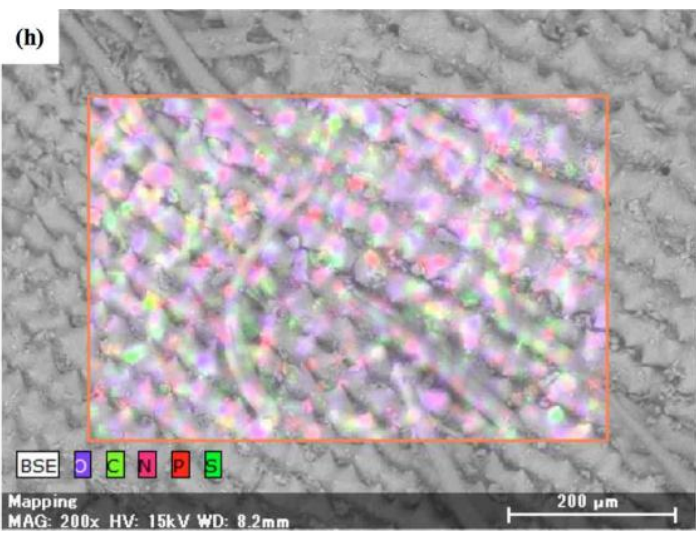

Fig. 5. Energy dispersive spectroscopy images of the (a) rice husks before pyrolysis and residues after pyrolysis for (b) condition I, (c) condition II, (d) condition III, (e) condition IV, (f) condition V, (g) condition VI and (h) condition VII.

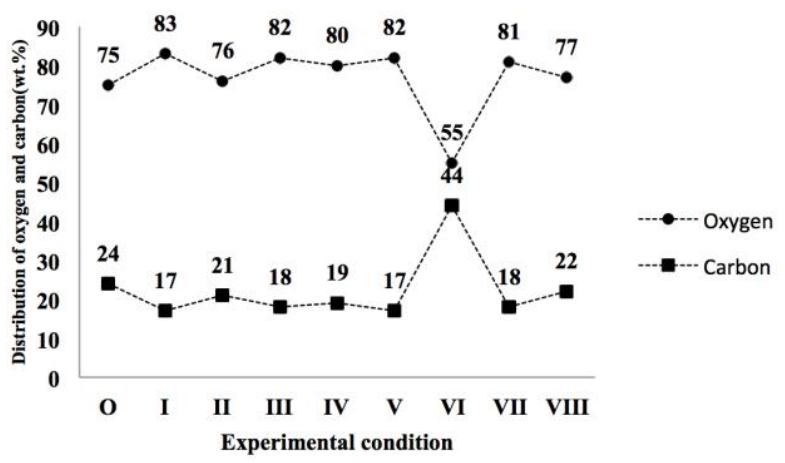

Fig. 6. Distribution of residual carbon and residual oxygen by EDS observation.

\section{CONCLUSION}

This research increased methane gas release during pyrolysis of rice husk by adding molecular sieves as a catalyst. Comparing additive conditions for pyrolysis, methane gas release is increased over that without additives by processing molecular sieves 3A into a powder form and using a 1:1 ratio. Molecular sieves were added uniformly and the powder form of molecular sieves is important to achieve a catalytic effect for methane release. In addition, the quantity of carbon dioxide emission is reduced using molecular sieve additives because of adsorption, but this is not sufficient for carbon neutral biomass utilization.

In this study, it was suggested that addition of additives in the form of powdered molecular sieve $3 \mathrm{~A}$ increases the content of methane while suppressing gas evolved, and can suppress the discharge of carbon dioxide.

\section{ACKNOWLEDGMENT}

This work was supported by Mr. Kathunori Suzuki of Tokyo Metropolitan Tama High School of Science and Technology, Japan. We are gratefully for the cooperation of Ms. Anon Shimizu and Ms. Tamaki Sasakawa in this study.

\section{REFERENCES}

[1] D. Ferdous and A. K. Dalai, "Production of $\mathrm{H}_{2}$ and medium Btu gas via pyrolysis of lignins in a fixed-bed reactor," Fuel Processing Technol, vol. 70, pp. 9-26, 2001.

[2] T. Bhaskar, T. Matsui, J. Kaneko, M. A. Uddin, A. Muto, and Y. Sakata, "Novel calcium based sorbent $(\mathrm{Ca}-\mathrm{C})$ for the dehalogenation 
$(\mathrm{Br}, \mathrm{Cl})$ process during halogenated mixed plastic (PP/PE/PS/PVC and HIPS-Br) pyrolysis," Green Chem, vol. 4, pp. 372-375, 2002.

[3] G. Grause, J. Ishibashi, T. Kameda, T. Bhaskar, and T. Yoshioka, "Kinetic studies of the decomposition of flame retardant containing high-impact polystyrene," Polym Degrad Stab, vol. 95, pp. 1129-1137, 2010.

[4] J. A. Onwudili, N. Insura, and P. T. Williams, "Composition of products from the pyrolysis of polyethylene and polystyrene in a closed batch reactor: Effects of temperature and residence time," J Anal Appl Pyrolysis, vol. 86, pp. 293-303, 2009.

[5] W. J. Hall and P. T. Williams, "Fast pyrolysis of halogenated plastics recovered from waste computers," Energ Fuel, vol. 20, pp. 1536-1549, 2006.

[6] T. Bhaskar, M. A. Uddin, K. Murai, J. Kaneko, K. Hamano, T. Kusaba, A. Muto, and Y. Sakata, "Comparison of thermal degradation products from real municipal waste plastic and model mixed plastics," J Anal Appl Pyrolysis, vol. 70, pp. 579-587, 2003.

[7] D. P. Serrano, J. Aguado, J. M. Escola, and E. Garagorri, "Performance of a continuous screw kiln reactor for the thermal and catalytic conversion of polyethylene-lubricating oil base mixtures," Appl Catal $B$, vol. 44, pp. 95-105, 2003.

[8] T. Bhaskar, T. Matsui, M. A. Uddin, J. Kaneko, A. Muto, and Y. Sakata, "Effect of $\mathrm{Sb}_{2} \mathrm{O}_{3}$ in brominated heating impact polystyrene (HIPS-Br) on thermal degradation and debromination by iron oxide carbon composite catalyst (Fe-C)," Appl Catal B, vol. 43, pp. 229-241, 2003.

[9] K. Murata, Y. Hirano, Y. Sakata, and M. A. Uddin, "Basic study on a continuous flow reactor for thermal degradation of polymers," J Anal Appl Pyrolysis, vol. 65, pp. 71-90, 2002.

[10] M. Blazso', Z. Cze'ge'ny, and C. Csoma, "Pyrolysis and debromination of flame retarded polymers of electronic scrap studied by analytical pyrolysis," J Anal Appl Pyrolysis, vol. 64, pp. 249-261, 2002.

[11] H. Bockhorn, A. Hornung, U. Hornung, P. Jakobstro"er, and M. Kraus, "Dehydrochlorination of plastic mixtures," J Anal Appl Pyrolysis, vol 49, pp. 97-106, 1999.

[12] M. Blazso' and E. Jakab, "Effect of metals, metal oxides, and carboxylates on the thermal decomposition processes of poly(vinyl chloride)," J Anal Appl Pyrolysis, vol. 49, pp. 125-143, 1999.

[13] R. Luijk, H. Haj, and L. Nelissen, "Formation of polybrominated dibenzofurans during extrusion of high-impact polystylene/decabromodiphenyl ether/antimony (III) oxide," Environ Sci Technol, vol. 26, pp. 2191-2198, 1992.

[14] A. Demirbas, "Biomass resource facilities and biomass conversion processing for fuels and chemicals," Energy Convers Manage, vol. 42, pp. 1357-78, 2001.

[15] J. J. Manya, E. Velo, and L. Puigjaner, "Kinetics of biomass pyrolysis: A reformulated three-parallel-reactions model," Ind Eng Chem, vol. 42, pp. 434-41, 2003.

[16] G. Varhegyi, J. J. M. Antal, E. Jakab, and P. Szabo, "Kinetic modeling of biomass pyrolysis," J Anal Appl Pyrolysis, vol. 42, pp. 73-87, 1997.

[17] K. Raveendran, A. K. Ganesh, and C. Khilar, "Influence of mineral matter on biomass pyrolysis characteristics," Fuel, vol. 74, pp. 1812-22, 1995.

[18] P. McKendry, "Energy production from biomass (part 1): Overview of biomass," Biores Technol, vol. 83, pp. 37-46, 2002.

[19] H. Ren, H. Lei, L. Wang, Q. Bu, S. Chen, and J. Wu, "Thermal behaviour and kinetic study for woody biomass torrefaction and torrefied biomass pyrolysis by TGA," Biosystems Engineering, vol. 116 , pp. 420-426, 2013.

[20] C. Couhert and J.-M. Commandre, "Sylvain Salvador, Is it possible to predict gas yields of any biomass after rapid pyrolysis at high temperature from its composition in cellulose, hemicellulose and lignin?" Fuel, vol. 88, pp. 408-41, 2009.

[21] S. Li and S. Xu et al., "Fast pyrolysis of biomass in free-fall reactor for hydrogen-rich gas," Fuel Processing Technol, vol. 85, pp. 1201-11, 2004.

[22] R. Zanzi and K. Sjostrom et al., "Rapid high-temperature pyrolysis of biomass in a free-fall reactor," Fuel, vol. 75, no. 5, pp. 545-50, 1996.

[23] A. Demirbas. "Gaseous products from biomass by pyrolysis and gasification: effects of catalyst on hydrogen yield," Energy Convers Manage, vol. 43, pp. 897-909, 2002.

[24] J. Corella, A. Monzon et al., "Ultra-fast biomass pyrolysis in a high-temperature $\left(2200^{\circ} \mathrm{C}\right)$, fluid-wall reactor," J Solar Energy Eng, vol. 110 , pp. $10-3,1988$.
[25] R. Zanzi and K. Sjostrom et al., "Rapid pyrolysis of agricultural residues at high temperature," Biomass Bioenergy, vol. 23, pp. 357-66, 2002.

[26] B. Bitowft, L. A. Andersson et al., "Fast pyrolysis of sawdust in an entrained flow reactor," Fuel, vol. 68, pp. 561-6, 1989.

[27] A. Demirbas, "Combustion characteristics of different biomass fuels, Prog," Energy Combust. Sci, vol. 30, pp. 219-230, 2004

[28] B. M. Jenkins, L. L. Baxter, T. R. Miles Jr., and T. R. Miles, "Combustion properties of biomass," Fuel Process Technol, vol. 54, pp. 17-46, 1998.

[29] R. H. H. Ibrahim, L. I. Darvell, J. M. Jones, and A. Williams, "Physicochemical characterisation of torrefied biomass," Journal of Analytical and Applied Pyrolysis, vol. 103, pp. 21-30, 2013.

[30] J. B. Gujar, M. A. Chaudhari, D. S. Kawade, and M. S. Shingare, "Molecular sieves: An efficient and reusable catalyst for multi-component synthesis of dihydropyrano [2,3-C]pyrazole derivatives," Tetrahedron Letters, vol. 55, pp. 6030-6033, 2014.

[31] A. V. Bridgwater and M. L. Cottam, Energy Fuels, vol. 6, no. 2, pp. 113- 120,1992

[32] E. Churin, "Energy, catalytic treatment of pyrolysis oils, cat. No. CD-NA-12480-EN-C," The Commission of the European Communities, Luxemboug, 1990.

[33] N. Morita, T. Wajima, and H. Nakagome, "Reduction in content of bromine compounds in the product oil of pyrolysis using synthetic hydrotalcite," International Journal of Chemical Engineering and Applications vol. 6, no.4, pp. 262-266, 2015.

[34] N. Morita, A. T. Saito, T. Wajima, and H. Nakagome, "Halogen reduction in pyrolysis oil from bromine-containing plastics using hydrotalcite," Advances in Environment Research, vol. 87, pp. 54-61, 2015.

[35] N. Morita, M. Nakayasu, A. T. Saito, T. Wajima, and H. Nakagome, "Effect of hydrotalcite on bromine content in oil produced from the pyrolysis of acrylonitrile-butadiene-styrene plastics," International Journal of Chemical Engineering and Applications, vol. 7, no. 4, pp 23-27, 2016.

[36] N. Morita, Y. Kawabata, A. T. Saito, T. Wajima, and H. Nakagome, "Effect of the bromine-based flame retardant plastic pyrolysis of hydrotalcite," MATEC Web of Conferences, vol. 62, 2016.

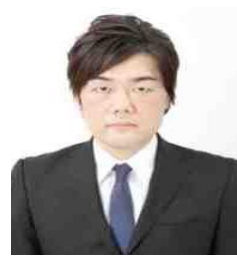

Naoyuki Morita was born in Japan in 1977. He completed the Chiba University Graduate School of Engineering in 2016, he has a $\mathrm{PhD}$. Specialty field is chemical engineering and environmental engineering.

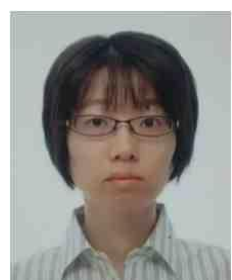

Masami Nakayasu was born in Japan in 1976. She learned the chemical and environmental engineering at Chuo University, Japan. Currently, we are studying environmental engineering at Chiba University Graduate School of Engineering.

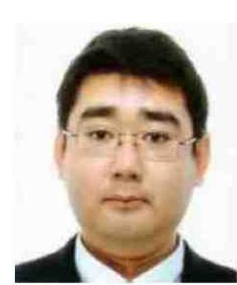

Yasumasa Kawabata was born in Aomori prefecture, Japan, in September, 1989. He received his associate degree in engineering from Hachinohe National College of Technology, Hachinohe, Aomori Prefecture, Japan in 2010, and his bachelor's and master's degrees in engineering from Chiba University, Chiba, Chiba Prefecture, Japan in 2012 and 2014, respectively.

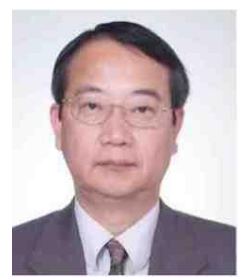

Hideki Nakagome was born in Japan 1951. He is a former Professor at Chiba University, Japan. He acquires a doctorate in Tokyo University. His specialty is environmental engineering and mechanical engineering. 